\title{
STUDY OF CYCLIC AND STEADY PARTICLE MOTION IN A REALISTIC HUMAN AIRWAY MODEL USING PHASE-DOPPLER ANEMOMETRY
}

\begin{abstract}
Jan JEDELSKÝ, František LíZAL, Miroslav JíCHA
Abstract: Transport and deposition of particles in human airways has been of research interest for many years. Various experimental methods such as constant temperature anemometry, particle image velocimetry and laser-Doppler based techniques were employed for study of aerosol transport in the past.

We use Phase-Doppler Particle Analyser (P/DPA) for time resolved size and velocity measurement of liquid aerosol particles in a size range 1 to $8 \mu \mathrm{m}$. The di-2ethylhexyl sabacate (DEHS) particles were produced by condensation monodisperse aerosol generator. A thin-wall transparent model of human airways with non-symmetric bifurcations and non-planar geometry containing parts from throat to 3rd-4th generation of bronchi was fabricated for the study. Several cyclic (sinusoidal) breathing regimes were simulated using pneumatic breathing mechanism. Analogous steady-flow regimes were also investigated and used for comparison.

An analysis of the particle velocity data was performed with aim to gain deeper understanding of the transport phenomena in the realistic bifurcating airway system. Flows of particles of different sizes in range $1-10 \mu m$ was found to slightly differ for extremely high Stokes numbers. Differences in steady and cyclic turbulence intensities were documented in the paper. Systematically higher turbulence intensity was found for cyclic flows and mainly in the expiration breathing phase. Negligible differences were found for behaviour of different particle size classes in the inspected range 1 to $8 \mu \mathrm{m}$. Possibility of velocity spectra estimation of air flow using the P/DPA data is discussed.
\end{abstract}

\section{INTRODUCTION}

Breathing as basic physiological activity brings people to an intense contact with aerosol particles. Exposure to PM air pollution is associated with app. $3 \%$ of mortality from cardiopulmonary disease, $5 \%$ of mortality from respiratory tract cancer, and $1 \%$ of mortality from respiratory infections in children (Cohen et al., 2005). A study performed by Cyris et al., 2010 on 112 participants show the people spent most of their time indoors $(63 \%)$, then in transit (car or public transport $(15 \%)$, walking or biking $(8 \%)$ ), and outdoors (5\%). They attributed peaks in exposure to ultrafine particles (UFP) to times spent in traffic while lowest levels of UFP to being at home; however, the personal indoor levels were somewhat higher than the ambient outdoor levels due to specific indo-

\footnotetext{
- Jan Jedelský, PhD., František Lízal, Prof. Miroslav Jícha, CSc., Department of Thermodynamics and Environmental Engineering, Faculty of Mechanical Engineering, Brno University of Technology, Technická 2896/2, 616 69, Brno, email: jedelsky@fme.vutbr.cz
}

This is an Open Access article distributed under the terms of the Creative Commons Attribution License 2.0, which permits unrestricted use, distribution, and reproduction in any medium, provided the original work is properly cited. 
or activities (passive smoking, cooking, cleaning). According to Klepeis et al., 2001 most individuals spend at least $85 \%$ of their time indoors where particulate matter (PM) concentrations are generally higher than outdoors (Fromme et al., 2007). Consonant results were found by Oeder et al., 2010 during investigation of indoor air PM10 collected in elementary school classrooms when compared to outdoor air PM10; the PM10 concentrations were 5.6 fold higher indoors than outdoors. Pilou et al., 2010 assert that people spend approximately $90 \%$ of their time indoors. They simulated a variety of domestic activities; smoking, sticks burning, grilling, frying, carpet cleaning, resuspension from movement on a carpet and use of sprays covering a broad range of particle size $0.3-20 \mu \mathrm{m}$. They measured deposition fraction for an adult male and a 5 year old child under particle exposure during movement on carpet. For both the cases particles in range $1-10 \mu \mathrm{m}$ dominated in trachea-bronchial tree deposition and mainly smaller particles up to $3 \mu \mathrm{m}$ were found in alveolar region.

Zangari et al., 2010 measured PM1, PM2.5 and PM10 concentrations within retirement homes and found them heavily dependent on external concentration. During the day, indoor PM concentration was higher than outdoor; PM10 was the highest of all due to a coarse particle re-suspension by internal activity.

Main targets of unwanted exposure to UFP, with a diameter of less than $100 \mathrm{~nm}$ are cardiovascular and pulmonary systems associated with a major public health issue which is viral lower respiratory tract infections in infants and young children (Van Woensel et al., 2003). An association between the time spent in traffic and the onset of myocardial infarction is documented in a case-crossover study (Peters et al., 2004). Fractions and components of the PM mixtures are associated with adverse health effects (Brunekreef et al., 2002) and a European threshold limit of $50 \mu \mathrm{g} / \mathrm{m}^{3}$ (daily limit, EU Directive $1999 / 30 / E G)$ was established in 2005. Black smoke was found to be a good indicator to link health effects with air pollution from combustion sources (Cassee et al., 2010) and diesel engine produced smoke has been used for assessment of particle effects on humans in laboratory conditions (Wierzbicka et al., 2010).

Aside of engine emissions also road and tyre wear have been found to contribute significantly to PM concentrations in near-traffic environments (Gustafsson et al., 2009). Deposition of road and tyre wear particles in the size interval $0.8-6 \mu \mathrm{m}$ was studied by Swietlicki et al., 2010). Wexler et al., 2010 found significant differences in rat airway architecture and lung function after long exposition to diffusion-flame and premixedflame carbon UFP (70 - $230 \mathrm{~nm}$ size). Dickens et al., 2010 studied regional deposition of tobacco smoke aerosol. They found count median diameter of the tobacco UFP about 160 $\mathrm{nm}$ with possible post puff coagulation.

The above mentioned studies show typical size range of the inhalable aerosol particles related with adverse health effects between $10 \mathrm{~nm}$ and $10 \mu \mathrm{m}$. We have limited our range of interest to $1-10 \mu \mathrm{m}$ looking not only to negative effects of environmental pollution but also for potentially interesting medical aerosol applications. Particle deposition occurs predominantly during the inhalation breathing phase so most flow studies are focused to inflow, but also exhalatory flow brings important information e. $\mathrm{g}$. for monitoring of lung disease using exhaled breath analysis. Mass median diameter of exhaled aerosol generated from surfactant film ranges between 0.7 and $2.8 \mu \mathrm{m}$ depending on various factors (Schwartz et al., 2010). More aspects of the flow and deposition of the aerosols that are of our concern are closely reviewed in Lizal et al. 2010. 
A challenge to understand how aerosols transport and deposit in human lungs drove us to application of P/DPA for particle velocity measurement in air flow. We use a realistic transparent human airway model and study transport of micron-size monodisperse liquid aerosol particles dispersed in air in different positions of this model. One of the key topics is behaviour of the aerosol particles carried in the air flow. Differences between velocity characteristics of the particles of different sizes and breathing conditions are documented in the paper using time resolved measurement of particle velocity. Estimation of the air flow based on the particle velocity data and other aspects of the particle seeding for P/DPA measurements are discussed. Finally a comparison between steady and cyclic particle flows is made in two positions of the airway model for three steady and three corresponding cyclic flow regimes.

\section{Experimental ApParatus}

Experimental equipment consists of a source of air flow and particles and P/DPA system. As a generator of oscillating flow, a computer controlled pneumatic mechanism is used. Monodisperse aerosol particles of DEHS ranging from 1 to $8 \mu \mathrm{m}$ are generated by condensation generator. One-half of the particles is mixed with the air in a chamber using static mixer and flows into the airway model (Fig. 1 left). The second half flows into a bladder that collects the air with particles for the second phase of breathing cycle.

1D Dantec P/DPA is used for measurement of particle size and mainly for time resolved measurement of axial velocity component of the particle movement during breathing
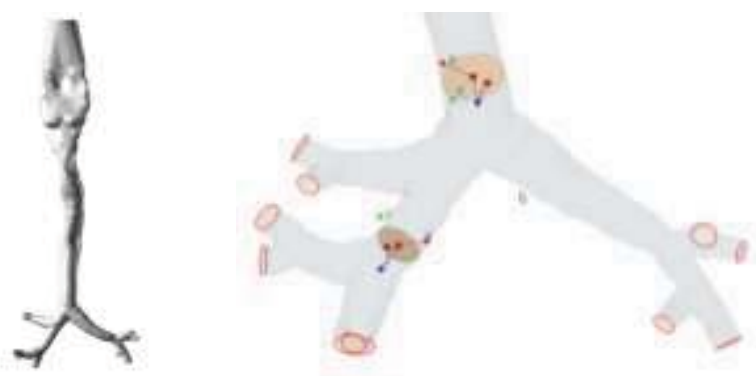

Figure 1: Airway model (left), measurement positions in trachea and bronchus intermedius (right). cycle in several positions of the model (Fig. 1 right). Transparent realistic human airway model with non-symmetric bifurcations and non-planar geometry was used for the investigation. The model covers airways from the throat to $3^{\text {rd }}-4^{\text {th }}$ generation of bronchi. Arrangement and description of our experimental device and the airway model is described in detail by Lizal et al., 2010.

\section{Data Acquisition and Processing}

The particle mixing system described above ensures relatively homogeneous air-particle mixture which pass through the measurement volume of P/DPA system. Although the aerosol is relatively dilute with concentration $c$ in range $10^{3}-10^{5}$ particles $/ \mathrm{cm}^{3}$, it enables high-frequency measurement of the velocity $v$ with mean data rate:

$$
\dot{n}=v \cdot c \cdot S
$$

in $\mathrm{kHz}$ range; $\mathrm{S}$ is cross-section area of the measurement system.

Presuming an equal particle distribution in space with a constant concentration and mean data rate of the measurement $\dot{n}$, the intervals $\Delta t$ between the particles are distributed exponentially: $p(\Delta t)=\dot{n} \cdot e^{-\dot{n} \cdot \Delta t}$, as seen in Fig. 2 right. The plot was constructed for steady state flow measurement. The most probable interparticle arrival times are zero. It means 
that information about very high frequency fluctuations is contained in the data. But the particle arrival times are irregular, see Fig. 2 left. Velocity measurement based on particles in flow (natural seeding) causes some troubles when one needs to calculate the mean or fluctuating velocity values or when spectral velocity properties needed (Tropea et al., 2001).

Even more complicated situation happens in the case of oscillatory flow where high velocities but also zero or near zero velocity values occur when the flow changes from inhalation to exhalation. Near zero velocity time instants are not possible to evaluate and corresponding results must not be used for analysis. Another problem rises from the dynamics of flow of the particles that are used for measurement. We use particles in range $1-8 \mu \mathrm{m}$ to study their flow and it would be convenient to utilise the particle velocity data also for calculation of the turbulence characteristics (e. g. velocity spectra) of the air flow. A question is if these particles are small enough to follow the air flow with sufficient precision for all the cases under investigation. This topic is discussed in the next chapter.
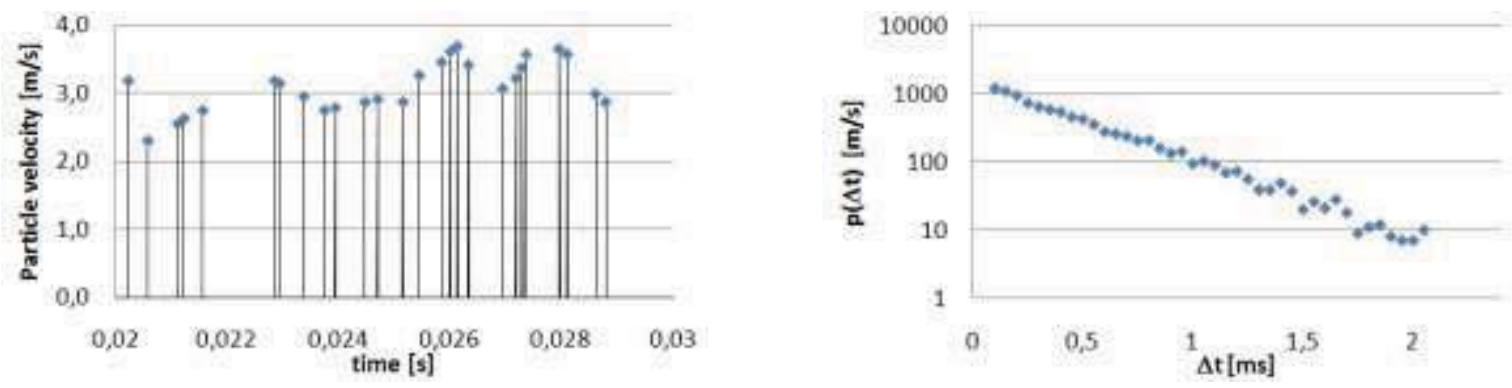

Figure 2: Time series of P/DPA velocity data (left) and frequency plot of arrival time between two particles for $1 \mu \mathrm{m}$ particles and flow rate $30 \mathrm{I} / \mathrm{min}$ in trachea $(0,0)$ (right).

Typical realisation of the P/DPA measurement of the cyclic particle flow is shown on Fig. 3. The measurement lasts for ten consequent breathing cycles (only four cycles are displayed). This number of cycles allows us to acquire statistically sufficient number of droplets for consequent analysis. Axial velocity, transit time and diameter of the DEHS particles flowing through the measurement volume are recorded. Fig. 3a shows axial velocity of the particles together with 20 -samples sliding average. Cyclic character of the mean flow is well reproduced, main flow structures are very similar in each cycle, only small cycle-to-cycle variations are seen. These variations can be attributed to the natural turbulence character of the flow. Diameter of the particles (Fig. 3b) keeps almost constant value during the run, so no significant particle coagulation appears. Number of the particles measured per time (data rate) is proportional to the particle velocity (Fig. 3c). It is inherent property of the laser Doppler technique and also other seeding based methods. Data rate depends on the velocity according to Eq. (1). Particle concentration (Fig. 3d) slightly increases from cycle to cycle and greater values are seen for exhalatory flow than for the inhalatory flow as particle generation continues through all the experiment and particles are directly introduced in the exhalatory flow. Decrease of the concentration during the inhalation phase is related to the particle deposition on the model and walls of connecting tubes. 

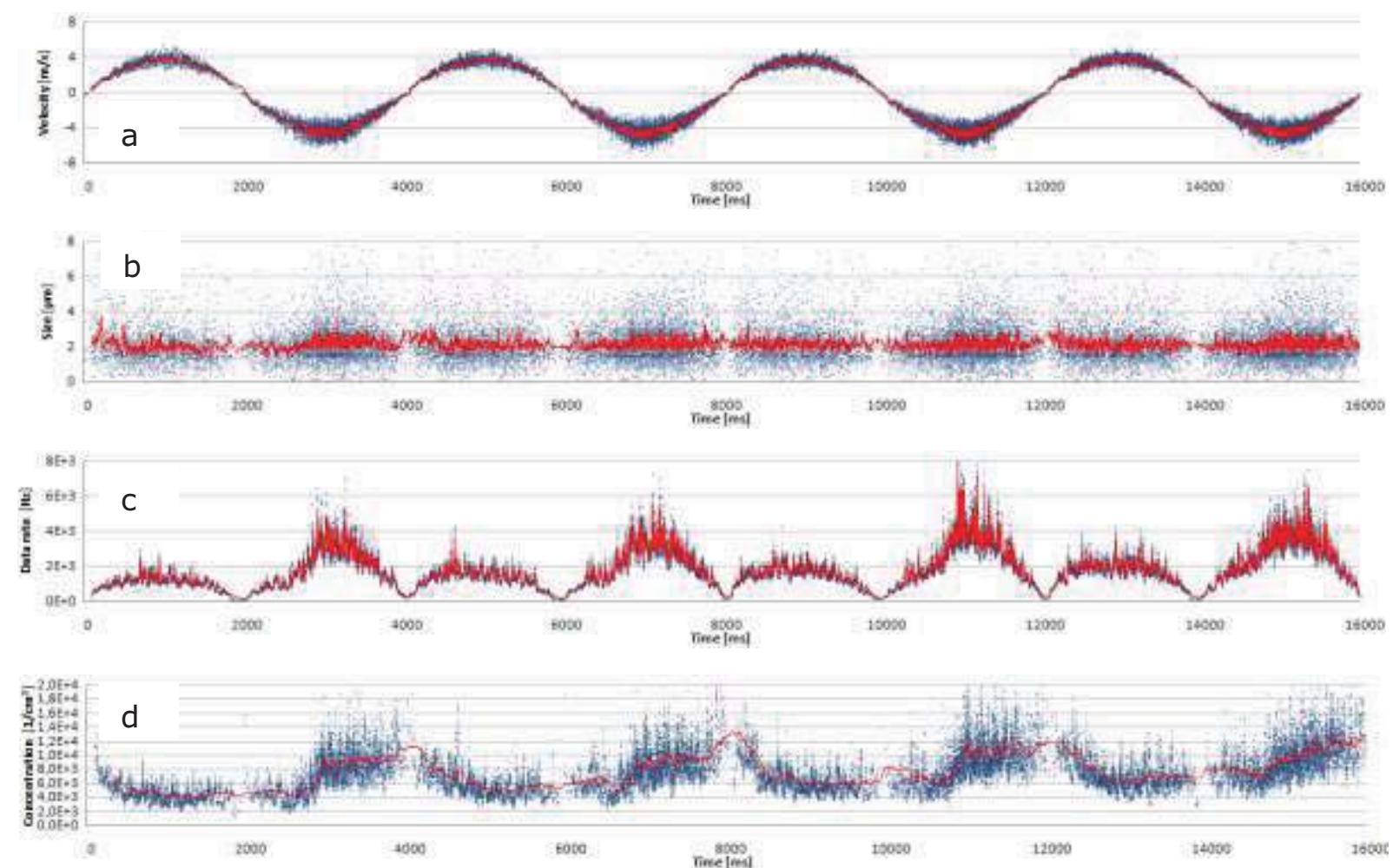

Figure 3: Exemplary result of the oscillatory flow measurement: 1 litre \& 4 sec., trachea axis, raw P/DPA data for 4 consequent cycles; a) axial velocity, b) diameter of the DEHS particles, $c$ ) data rate and d) particle concentration.

The P/DPA measures axial velocity, size and arrival time of individual aerosol particles. Temporally resolved mean and fluctuating axial velocity and resulting turbulence

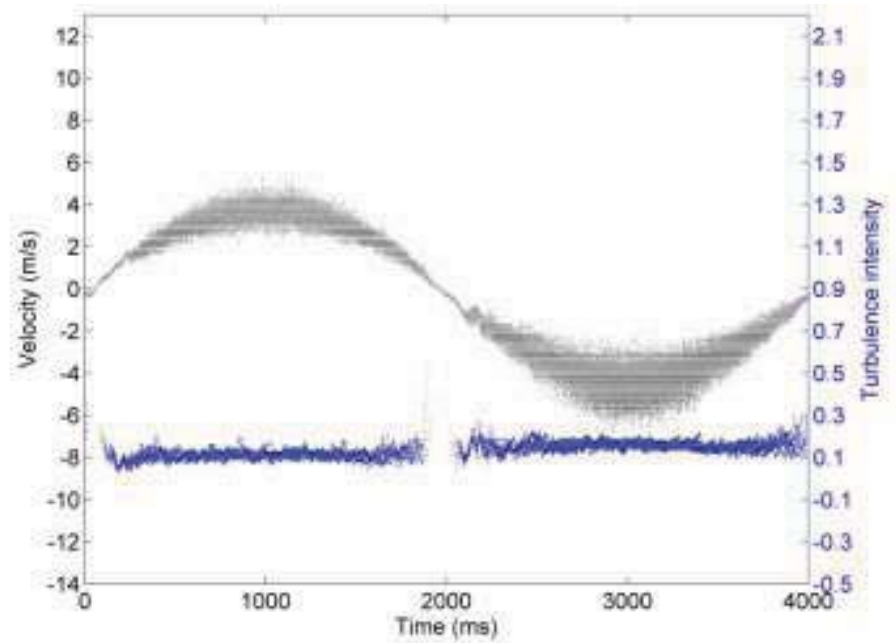
intensity were evaluated. Data from several cycles were overlapped to produce one average cycle (Fig. 4). Data processing for calculation of the axial turbulence intensity is described in Jedelsky et al., 2010.

Figure 4: Average cycle, 1 litre \& 4 sec., trachea axis; results of velocity (black dots) and turbulence intensity (blue dots) for ten cycles phase-averaged.

\section{Particle Size}

It is well known that deposition efficiency of the aerosol particles in different human lungs positions significantly depends on the breathing conditions - flow rate and local velocity, on character of the flow (abrupt changes of the flow direction) and on the particle size. All these parameters can be covered with a unique non dimensional parameter. Stokes number $(S t)$ or impact factor are the most often used ones. Our study 
covers range $0.0005<$ St $<0.12$ (according Jedelsky et al., 2010), so in all the cases particles should follow the air flow relatively closely. We have prepared a test to compare behaviour of small particles (mean size $\mathrm{d}=0.5 \mu \mathrm{m}$ with $S t=0.00098$ ), middle size particles $(\mathrm{d}=2.5 \mu \mathrm{m} \& S t=0.024)$ and large particles $(\mathrm{d}=6.1 \mu \mathrm{m} \& S t=0.15)$.

Light activity regime with $V_{t}=1.5$ litre and period $3 \mathrm{~s}$ was used. The test was made in left

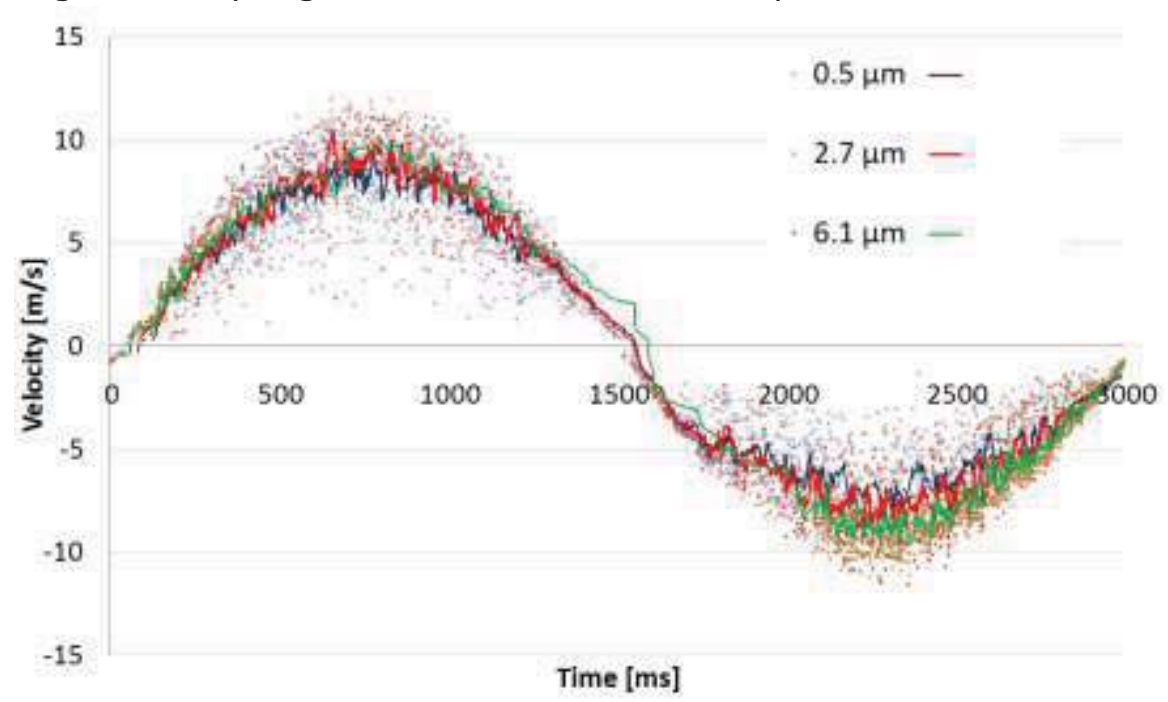

lung in the $4^{\text {th }}$ generation of bronchi in axial position with polydisperse particles in size range $0-10$ $\mu \mathrm{m}$. A phase averaging with grouping of the particles from ten cycles into one average cycle was made. Size discrimination into three size classes

Figure 5: Average cycle with polydisperse particles $0-10 \mu \mathrm{m}, 4^{\text {th }}$ generation $(0,0), V_{t}=1.5$ litre $\& T=3 \mathrm{~s}$.

covering each approximately the same number of 1700 particles was performed afterwards: size range $0.2-0.7 \mu \mathrm{m}$ with mean size $0.5 \mu \mathrm{m}, 2.6-2.8 \mu \mathrm{m} \& 2.5 \mu \mathrm{m}, 4.5$ $-10 \mu \mathrm{m} \& 6.1 \mu \mathrm{m}$. Ten-samples sliding average was made for each size class. Resulting curves show that particles in all the size classes follow the mean flow; not only the basic sinusoidal cycle shape but also abnormalities seen at the beginning of the inhalatory flow phase $(\sim 100 \mathrm{~ms})$ and in rising exhalatory flow $(\sim 1900 \mathrm{~ms})$. Low particle number in size class $6.1 \mu \mathrm{m}$ caused an artificial declination of the $6.1 \mu \mathrm{m}$ curve from the
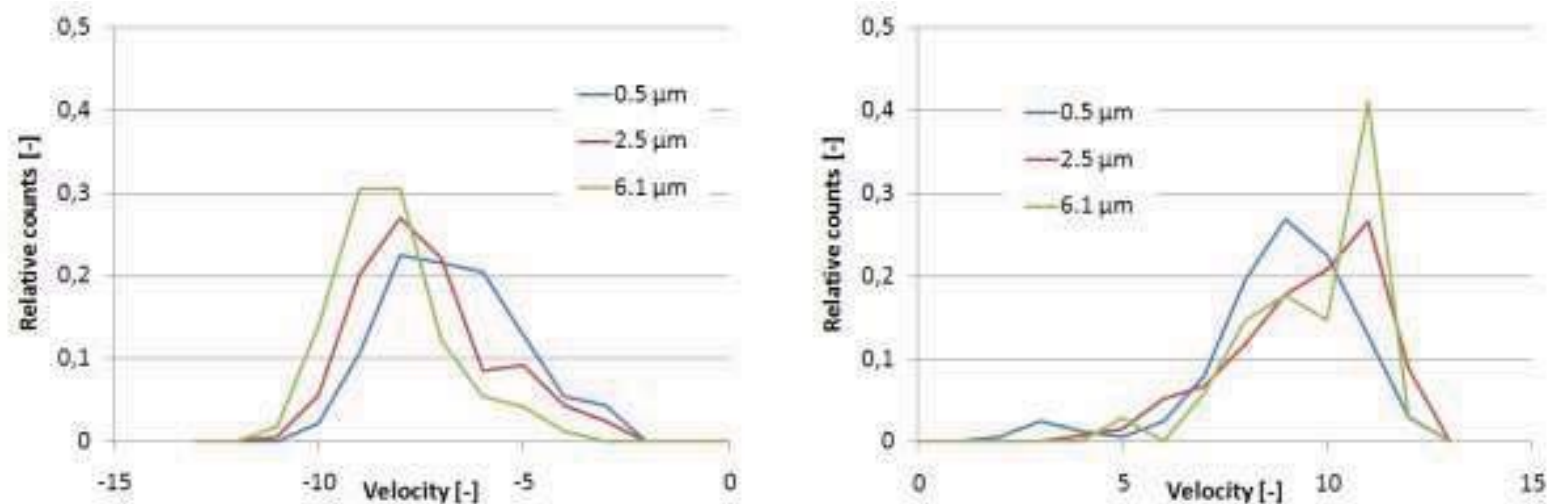

Figure 6: PDF of velocity for peak inhalation in time window 650 - $850 \mathrm{~ms}$ (left) and in peak exhalation $2150-2350 \mathrm{~ms}$ (right), $4^{\text {th }}$ generation $(0,0), V_{t}=1.5$ litre $\& T=3 s$. 
other curves. The three curves show systematic difference in the places of great flow velocity; the difference seems to be proportional to the velocity and larger particles have greater velocity. It is obvious as also $S t$ is directly proportional to velocity with direct proportion. Exhalatory flow differs more significantly than inhalatory flow which probably corresponds with tube geometry.

Probability density function (PDF) of the particle velocity was evaluated for all three size classes in particular time windows to find out more about the differences. Inhalatory time window was set from $650 \mathrm{~ms}$ to $850 \mathrm{~ms}$, exhalatory time window was set from $2150 \mathrm{~ms}$ to 2350 ms. Fig. 6 shows that small particles have the PDF roughly similar to the normal distribution while for large particles it tend to be more skew. Already PDF for $2.5 \mu \mathrm{m}$ particles differs from the PDF for $0.5 \mu \mathrm{m}$ particles. These findings acquired for the extremely high St show that only small particles follow air flow closely and only their velocity data could be used for calculation of the velocity turbulence characteristics of the air flow. Common measurements made at resting or normal breathing conditions in positions with moderate velocity enables to use also particles larger than $1 \mu \mathrm{m}$ (typically up to $4 \mu \mathrm{m}$ ) for the air velocity estimation.

\section{Steady ANd Cyclic Flows}

Steady and cyclic particle flow measurements were investigated in two positions of the airway model (Fig. 1 right): a point placed in trachea centreline near bifurcation and a point $4 \mathrm{~mm}$ off the centreline of bronchus intermedius (B.I.). Three steady breathing conditions (15, 30 and 60 litre/min) and three corresponding cyclic sinusoidal breathing conditions were used (tidal volume 0.5 litre and breathing period $4 \mathrm{~s}, 1$ litre \& $4 \mathrm{~s}$ and 1.5 litre \& $3 \mathrm{~s}$ ). Three different particle sizes were used: 1,4 and $8 \mu \mathrm{m}$. Plots of the velocity and turbulence profiles for full breathing cycle together with discussion of specific findings were already presented in our earlier paper (Jedelsky et al., 2010). Turbulence intensities at the steady and cyclic flows are compared in Table 1. Mean turbulence intensity at the cyclic flows is calculated as an average value during phase window $(0.3 \pi$ $-0.7 \pi)$ for the inspiration and $(1.3 \pi-1.7 \pi)$ for the expiration phases respectively.

Table 1: Turbulence intensity in trachea at steady and cyclic flow regimes.

\begin{tabular}{|c|c|c|c|c|c|c|c|c|c|c|c|c|c|}
\hline \multirow{3}{*}{$\begin{array}{l}\text { Pos. } \\
(\mathrm{mm})\end{array}$} & \multirow{3}{*}{$\begin{array}{l}\text { Size } \\
(\mu \mathrm{m})\end{array}$} & \multicolumn{6}{|c|}{ Turbulence intensity (-), steady } & \multicolumn{6}{|c|}{ Turbulence intensity (-), cyclic } \\
\hline & & \multicolumn{3}{|c|}{$\begin{array}{l}\text { Inspiration } \\
\text { (litre/min) }\end{array}$} & \multicolumn{3}{|c|}{$\begin{array}{c}\text { Expiration } \\
\text { (litre/min) }\end{array}$} & \multicolumn{3}{|c|}{$\begin{array}{l}\text { Inspiration } \\
\text { (litre/min) }\end{array}$} & \multicolumn{3}{|c|}{$\begin{array}{l}\text { Expiration } \\
\text { (litre/min) }\end{array}$} \\
\hline & & 15 & 30 & 60 & 15 & 30 & 60 & 15 & 30 & 60 & 15 & 30 & 60 \\
\hline 0 & 1 & 0.104 & 0.085 & 0.071 & 0.113 & 0.140 & 0.125 & $\mathrm{NaN}$ & 0.092 & $\mathrm{NaN}$ & $\mathrm{NaN}$ & 0.157 & $\mathrm{NaN}$ \\
\hline 0 & 4 & 0.107 & 0.110 & 0.091 & 0.124 & 0.142 & 0.115 & 0.095 & 0.097 & 0.084 & 0.199 & 0.191 & 0.155 \\
\hline 0 & 8 & 0.109 & 0.092 & 0.074 & 0.146 & 0.140 & 0.122 & $\mathrm{NaN}$ & 0.095 & $\mathrm{NaN}$ & $\mathrm{NaN}$ & 0.169 & $\mathrm{NaN}$ \\
\hline-4 & 1 & 0.068 & 0.066 & 0.069 & 0.181 & 0.108 & 0.132 & $\mathrm{NaN}$ & $\mathrm{NaN}$ & $\mathrm{NaN}$ & $\mathrm{NaN}$ & $\mathrm{NaN}$ & $\mathrm{NaN}$ \\
\hline-4 & 4 & 0.073 & 0.067 & 0.067 & 0.179 & 0.116 & 0.137 & $\mathrm{NaN}$ & $\mathrm{NaN}$ & $\mathrm{NaN}$ & $\mathrm{NaN}$ & $\mathrm{NaN}$ & $\mathrm{NaN}$ \\
\hline-4 & 8 & 0.071 & 0.069 & 0.067 & 0.183 & $\mathrm{NaN}$ & $\mathrm{NaN}$ & $\mathrm{NaN}$ & $\mathrm{NaN}$ & $\mathrm{NaN}$ & $\mathrm{NaN}$ & $\mathrm{NaN}$ & $\mathrm{NaN}$ \\
\hline
\end{tabular}

\subsection{Steady-State Flow in TRAChea AND BRONChus INTERMEdius}

Turbulence intensity at both positions does not significantly depend on the particle size in the inspected range $1-8 \mu \mathrm{m}$. Turbulence intensity is always significantly larger at 
expiration flow and it usually moderately decreases with flow rate for both the inspiratory and expiratory flows. Turbulence intensity in the B.I. is always lower than in trachea. It can be explained by more complicated geometry in trachea, mainly by a presence of the so called laryngeal jet and also by higher Reynolds numbers $(R e)$ in trachea.

Power spectral density (PSD) of velocity fluctuations were calculated for inspiratory flow for regime $30 \mathrm{l} / \mathrm{min}$ in trachea axis using a slot correlation technique (Benedict et al., 2000) using a program Kern (Nobach et al., 2002). Spectral characteristics of three size classes: 1, 4 and $8 \mu \mathrm{m}$ particles were estimated, see Fig. 7 left. No systematic difference between the three different PSDs was found. Maximum Stokes number is 0.04 for $8 \mu \mathrm{m}$ particles and flow rate $30 \mathrm{l} / \mathrm{min}$. All other cases under investigation give smaller St. The particles therefore should follow the air flow and it is possible to use their velocity as approximation of the air flow velocity. The intensity of fluctuations is approximately constant up to about $50 \mathrm{~Hz}$ with decreasing tendency for higher frequencies afterwards. PDF of the particle velocity is evaluated in Fig. 7 right. The velocity distribution is similar to the log-normal distribution with moderate inclination of the maximum to higher velocities. This bias is caused by specific P/DPA sampling rate, where for spatially uniform particle concentration the data rate is proportional to the actual flow velocity (Eq. (1)). Plots for different particle sizes show similar shape, no significant difference between them is found.
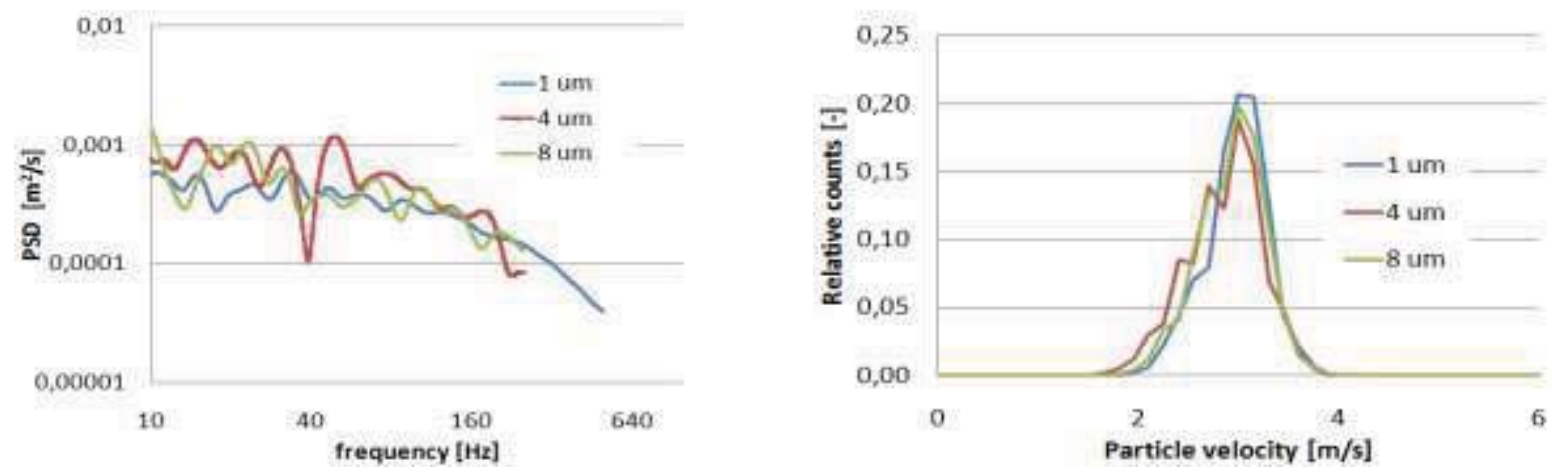

Figure 7: PSD of particles at steady flow conditions $301 / \mathrm{min}$ in trachea axis (left), Velocity PDF (right).

\subsection{CyCLIC FLow in TRACHEA}

Results acquired under cyclic flow conditions exhibit more complex behaviour compared to the data at steady flows (Jedelský et al., 2010). The turbulence intensity level in trachea (Table 1 ) is always smaller in the inspiration than in the expiration part of the cycle.

Particles in trachea move with higher turbulence intensity level during each cycle phase than particles in the B.I. Reynolds numbers in trachea are significantly larger than in the B.I. for corresponding breathing conditions; the trachea $R e$ is close to transition laminarturbulent flow for normal breathing and it is definitely in turbulent flow regime in the case of light activity breathing. The results indicate that laryngeal jet is present in the trachea measurement position for all the regimes inspected. Flow in the B.I. (not evaluated here) is virtually laminar (according to $R e$ ) at resting conditions and the 
change into turbulent flow at regimes with higher flow rates is probably due to increase in $R e$ and mixing of flows in bifurcation.

Comparison of turbulence intensity in trachea for steady and cyclic flow regimes can be done using data in Table 1. Turbulence intensity in the inspiration phase of the cyclic flow regimes is relatively similar or only slightly higher than the turbulence intensity in steady flow regimes. Turbulence intensity in the expiration phase of the cyclic flow regimes is systematically higher than the turbulence intensity in steady flow regimes. This difference is probably related to the contact and mixing of the streams from daughter branches.

\section{Conclusions}

The paper documents suitability of the laser-Doppler technique combined with the transparent human airway model for time resolved measurement of the particle flow velocity under steady as well as under oscillatory flows. Specific distribution of the interparticle arrival time was shown and discussed. Measurement difficulties in the zero velocity crossing (passing from inhalation to exhalation) were shown.

Particle size in the inspected range $1-10 \mu \mathrm{m}$ was found to influence the dynamic behaviour of aerosol only in the extreme cases: differences between the smallest and the greatest droplets, light activity regime and in the airway positions and phase of the cycle with great flow velocities.

Steady and cyclic flows exhibit different behaviour with different turbulence intensity. The turbulence is usually higher for inhalatory cyclic flows and always significantly higher for expiration cyclic flows.

\section{ACKNOWLEDGEMENTS}

This work was supported by the project GA101/07/0862 funded by the Czech Science Foundation, project OC10052, COST Action Particles No. MP0806, funded by the Ministry of Education, Youth and Sports of the Czech Republic and from the Brno University of Technology project BD 13001007.

\section{REFERENCES}

[1] Benedict, L. H., Nobach, H. and Tropea, C. (2000), Estimation of turbulent velocity spectra from laser Doppler data, Meas. Sci. Technol. 11, 1089.

[2] Brunekreef, B. et al., (2002), Air pollution and health. Lancet, 360(9341): p. 123342.

[3] Cassee, F., Gerlofs-Nijland, M., Fischer, P., Gosens, I. \& Janssen, N., (2010), Coherence between epidemiological observations and toxicological hazard assessments for ambient particulate matter: about metrics and indicators, International Aerosol Conference, Helsinki.

[4] Cohen, A.J., Anderson, H.R., Ostro, B., Pandey, K.D., Krzyzanowski, M., Künzli, N., Gutschmidt, K., \& Smith, K. (2005) J. of Toxicology and Environmental Health - Part A, 68, 1301-1307.

[5] Cyrys, J., Hänninen, O. O., Pitz, M., Kraus, U., Hampel, R., Wichmann, H. E. \& Peters, A. (2010), Personal exposure to ultrafine particles in different microenvironments, International Aerosol Conference, Helsinki. 
[6] Dickens, C., McGrath, C., Perkins, J., Zhuravskaya, A., Biggs, P., McAughey, J., (2010), Measuring the regional deposition of tobacco smoke in the human respiratory system, International Aerosol Conference, Helsinki.

[7] Fromme, H. et al., (2007), Particulate matter in the indoor air of classroomsexploratory results from Munich and surrounding area, Atmos. Environ., 41, 854866.

[8] Gustafsson M., Blomqvist, G., Gudmundsson, A., Dahl, A., Jonsson, P. \& Swietlicki, E. (2009). Factors influencing PM10 emissions from road pavement wear. Atm. Env., 43, 4699-4702.

[9] Jedelský, J., Lízal, F. \& Jícha, M. (2010), " Particle Motion in a Realistic Human Airway Model under Steady and Cyclic Flows", In proceedings XXIV. Symposium on Anemometry, Praha, Institute of Hydrodynamics ASCR, p. 1 - 9.

[10] Klepeis, N. E. et al., (2001), The National Human Pattern Survey (NHAPS): a resource for assessing exposure to environmental pollutants, J. Expo. Anal. Environ. Epidemiol., 11, 231-252.

[11] Lizal, F., Jedelsky, J., Elcner, J., Durdina, L., Halasova, T., Mravec, F. And Jicha, M., (2010), Research of Transport and Deposition of Aerosol in Human Airway Replica, in proceedings of Experimental Fluid mechanics, in print.

[12] Nathan, C. A., \& Seid, A. B., (1997), Int J Pediatr Otorhinolaryngol. 39: 59-65.

[13] Nobach, H. (2002), "Local time estimation for the slotted correlation function of randomly sampled LDA data", Experiments in Fluids 32, 337-345.

[14] Oeder, S., Schober, W., Weichenmeier, I., Schierl, R., Dietrich, S., Fromme, H., Lintelmann, J., Behrendt, H. \& Buters, J.T.M., (2010), Differential gene expression of inflammatory and xenobiotic metabolizing genes after exposure to elementary classroom indoor/outdoor PM10, International Aerosol Conference, Helsinki.

[15] Peters, A., von Klot, S., \& Löwel, H. (2004), N. Engl. J. Med., 351, (17): 17211730.

[16] Pilou, M., Saraga, D., Tsangaris, S., Vasilakos, C. and Housiadas, C. (2010), Particle deposition in the lung during domestic activities, International Aerosol Conference, Helsinki.

[17] Schwarz, K., Dunkhorst, W., Lödding, H., Windt, H. \& Koch, W., (2010), Investigations into the mechanism and site of droplet generation in the human lung, International Aerosol Conference, Helsinki.

[18] Swietlicki, E., Löndahl, J., Rissler, J., Gudmundsson, A., Gustafsson, M., Blomqvist, G. and Lundqvist, A. (2010), Measurements of Respiratory Deposition of Road-Wear Particles, International Aerosol Conference, Helsinki.

[19] Tropea, C., Nobach, H., Ramond, A., Reulet, P. (2001), "Turbulent Velocity Spectra from Laser Doppler Data", Proc. 3rd ONERA - DLR Aerospace Symposium, Paris, France.

[20] Van Woensel, J. B. M., Van Aalderen, W. M. C. \& Kimpen, J. L. L. (2003), Br Med J. 327:36-40.

[21] Wexler, A., Lee, D., Wallis, C., Schelegle, E., Van Winkle, L., Kumfer, B., Kennedy, I. and Chan, J., (2010), Changes in structure and function in adult rat lungs due to post-natal exposure to ultrafine PM and ozone, International Aerosol Conference, Helsinki.

[22] Wierzbicka, A., Albin, M., Andersson, U.B.K., Assarsson, E., Axmon, A., Barregård, L., Berglund, M., Bohgard, M., Broberg, K., Brunskog, J., Gudmundsson, A., 
Gunnskog, A., Hagerman, I., Jönsson, B., Kåredal, M., Nilsson, P., Österberg, K., Pagels, J., Poulsen, T., Rissler, J., Stockfelt, L., \& Sällsten, G., (2010), A methodology for assessment of combined effects of particles and noise on humans during controlled chamber exposure, International Aerosol Conference, Helsinki.

[23] Zangari, R., Cetta, F., Guercio, V., Schiraldi, G., Sala, M., Mandelli, M., Laviano, P., Dellanoce, C., Accinni, R. and Allegra, L., (2010) The impact of traffic pollution on antioxidant system of two populations exposed to different levels of pollutants: estimation of redox status of thiols, International Aerosol Conference, Helsinki. 